\title{
A Survey on Cellular and Engineered Tissue Therapies in Europe in 2008
}

\author{
Ivan Martin, Ph.D., ${ }^{1, *}$ Helen Baldomero, ${ }^{2, *}$ Alan Tyndall, M.D. ${ }^{3,{ }^{*}}$ \\ Dietger Niederwieser, M.D., ${ }^{4, *}$ and Alois Gratwohl, M.D.,"*
}

Cellular therapy is an evolving investigational treatment modality in regenerative medicine, but little published information is available on its current use. Starting from the established European group for Blood and Marrow Transplantation activity survey on hematopoietic stem cell transplantation, a joint committee of four major scientific organizations made a coordinated attempt to collect detailed information in Europe for the year 2008. Thirty-three teams from 16 countries reported data on 656 patients to a "novel cellular therapy" survey, which were combined to additional 384 records reported to the standard European group for Blood and Marrow Transplantation survey. Indications were cardiovascular (29\%; 100\% autologous), musculoskeletal (18\%; 97\% autologous), neurological (9\%; 39\% autologous), epithelial/parenchymal (9\%; 18\% autologous), autoimmune diseases (12\%; 77\% autologous), or graft-versus-host disease (23\%; $13 \%$ autologous). Reported cell types were hematopoietic stem cells $(39 \%)$, mesenchymal stromal cells $(47 \%)$, chondrocytes $(5 \%)$, keratinocytes $(7 \%)$, myoblasts $(2 \%)$, and others (1\%). In $51 \%$ of the grafts, cells were delivered after expansion; in $4 \%$ of the cases, cells were transduced. Cells were delivered intravenously $(31 \%)$, intraorgan $(45 \%)$, on a membrane or gel $(14 \%)$, or using three-dimensional scaffolds $(10 \%)$. This data collection platform is expected to capture and foresee trends for novel cellular therapies in Europe, and warrants further consolidation and extension.

\section{Introduction}

S TEM CELL THERAPIES are defined as "treatment in which stem cells are induced to differentiate into the cell type required to repair damaged or destroyed cells or tissues" (www.stemcells.nih.gov/info/glossary.asp). The most familiar example is hematopoietic stem cell (HSC) transplantation. However, more recently, stem, progenitor, and differentiated cells of various lineages are increasingly being employed as "novel cellular therapy," exploiting not just their ability to differentiate and repair, but also their capacity to home to damaged tissues and perform local paracrine healing and protective functions. As many disparate specialty groups are now involved, it is difficult to obtain an overview of these activities.

The annual activity report by the European Group for Blood and Marrow Transplantation (EBMT) has become an established instrument to observe trends and to monitor changes in the use of HSC transplants for the treatment of hematologic disorders in Europe. ${ }^{1-5}$ The activity survey does not provide any data on outcome, on the age or sex of patients, or on their pre- and posttransplant therapy. The goal of the data collection is the rapid dissemination of the status quo in the field of HSC therapies, to provide a formal basis for patient counseling and health care planning. Long-term analyses provided evidence that the survey can foresee trends with high predictability and very rapidly. In the past years, for example, the activity survey was able to capture the increasing use of cord blood as a stem cell source, the change from bone marrow to peripheral blood, or the utilization and integration of unrelated donor transplants. ${ }^{6}$

In 2007, the EBMT report included for the first time information on treatments based on mesenchymal stromal cells or on HSC for nonhematological indications. ${ }^{6}$ The collected information confirmed the importance of mesenchymal stromal cell grafts ${ }^{7}$ and the use of HSC for cardiovascular and neurological disorders, as well as for tissue repair. ${ }^{8-10}$ However, the structure of the distributed form did not allow capturing

\footnotetext{
${ }^{1}$ Departments of Surgery and of Biomedicine, University Hospital, Basel, Switzerland.

${ }^{2}$ EBMT Activity Survey Office, Hematology, University Hospital, Basel, Switzerland.

${ }^{3}$ Department of Rheumatology, Felix Platter Hospital, Basel, Switzerland.

${ }^{4}$ Department of Hematology, University Hospital, Leipzig, Germany.

*The Joint Survey Committee of the Tissue Engineering and Regenerative Medicine International Society (TERMIS), Europe; the International Cartilage Repair Society (ICRS); the European League Against Rheumatism (EULAR); the International Society for Cellular Therapy (ISCT), Europe; and the European Group for Blood and Marrow Transplantation (EBMT).
} 
several relevant features of the novel cellular therapy transplants (e.g., those related to the cell processing and delivery mode). Moreover, since those grafts are frequently performed outside the traditional hematology units, it became apparent that involvement of additional working groups was necessary to increase the relevance of the program.

In 2008, the European sections of the Tissue Engineering and Regenerative Medicine International Society (TERMISEU), of the International Society of Cellular Therapy (ISCTEurope), and of the International Cartilage Repair Society (ICRS) have for the first time coordinated a joint initiative with the EBMT and the European League Against Rheumatism (EULAR) to establish a comprehensive, quantitative map of patients being treated in Europe with specific cell types, sorted by the cell processes, and delivery modes used. In this article, we report the results of the first survey for the activity in 2008 and provide a perspective for a further extended and consolidated program for the years to come.

\section{Patients and Methods}

\section{Data collection and validation}

Participating teams were requested to report their data for 2008 by indication, cell type and source, donor type, processing method, and delivery mode. The survey followed the traditional principles of the EBMT, concentrating on numbers of patients with a first cellular therapy. For EBMT teams not using the full questionnaire, information on cellular therapies was limited to numbers of HSC for nonhematopoietic use, mesenchymal stromal cell-based therapies (later identified to be exclusively related to treatment of graft-versus-host disease), and donor type. Questionnaires were collected by paper forms or electronically. Quality control measures, for EBMT members only, included several established independent systems: confirmation of validity of the entered data by the reporting team, selective comparison of the survey data with MED-A data sets in the EBMT ProMISE data system, cross checking with the National Registries, and onsite visits of selected teams. No quality control system could be applied for the non-EBMT reporting teams yet.

\section{Teams}

Members of the 4 participating societies from 47 countries (39 European and 8 affiliated countries) were contacted for the 2008 report (EBMT survey). The non-European countries affiliated with the EBMT were Algeria, Iran, Israel, Jordan, Lebanon, Saudi Arabia, South Africa, and Tunisia. Thirtythree teams in 16 countries (14 European and 2 affiliated countries) reported novel cellular therapies using the survey form, with detailed information on indication, cell source and type, donor type, processing, and delivery mode. Additional 58 teams from 21 countries (19 European and 2 affiliated countries) reported treatments using the standard EBMT activity survey, allowing to include only limited information. Responding teams are listed in the Appendix in alphabetical order by country, city, and EBMT center code (if applicable), along with the total numbers of reported cellular therapies. According to the information received, there were no cellular therapies (including HSC transplants) performed in Albania, Andorra, Armenia, Georgia, Liechtenstein, Malta, Moldavia, Monaco, Montenegro, San Marino, and The Vatican in 2008.

\section{Transplant rates}

Transplant rates, defined as numbers of cellular therapies per 10 million inhabitants, were computed for each country, without adjustments for patients who crossed borders or received treatment in a foreign country. Population numbers were obtained from the U.S. Census Office database (www .census.gov).

\section{Results}

\section{Number of novel cellular therapies and disease indications}

According to the received reports, a total of 1040 patients were treated with novel cellular therapies, 376 (36\%) with allogeneic and 664 (64\%) with autologous cells (Table 1). Main indications were cardiovascular disorders (29\%; 100\% autologous), musculoskeletal disorders (18\%; 97\% autologous), neurological disorders (9\%; 39\% autologous), epithelial disorders (9\%; 18\% autologous), autoimmune diseases $(12 \%$; $77 \%$ autologous), and graft-versus-host disease (23\%; 13\% autologous).

From 656 patients, more detailed information was obtained concerning indications. Among the cardiovascular disorders, myocardial ischemia $(n=185)$, bypass grafts $(n=43)$, and cardiomyopathy $(n=13)$ were the most frequently reported indications. Among the musculoskeletal disorders, cartilage repair $(n=90)$ and bone repair $(n=24)$ were the main reason for a cellular therapy. Skin reconstruction $(n=36)$ and liver insufficiency $(n=11)$ were the two main reported indications for epithelial/parenchymal disorders. Neurological indications only included unspecified disorders $(n=36)$. About $127(19 \%)$ of all cellular therapies were for autoimmune disorders; in this category, multiple sclerosis $(n=77)$ was the leading subgroup, followed by other neurological indications $(n=20)$.

\section{Cell type, source, and donor type}

Of the 406 HSC treatments, $84 \%$ were autologous transplants and $70 \%$ were used to treat cardiovascular diseases (Table 1). All 48 chondrocyte and 16 myoblast transplants were autologous. Of the 491 mesenchymal stromal cellbased therapies, $49 \%$ were allogeneic.

In the detailed survey, mesenchymal stromal cells were obtained from bone marrow in all 251 cases and mostly used to treat musculoskeletal $(33 \%)$, neurological $(12 \%)$, and autoimmune disorders (51\%). For the 262 HSC treatments, cells were derived from the bone marrow $(70 \%)$, placenta $(3 \%)$, and peripheral blood (27\%). The donor type was associated with the disease indication: autologous cells were used predominantly for cardiovascular $(47 \%)$ and musculoskeletal $(25 \%)$ disorders, whereas allogeneic cells were used exclusively for autoimmune (72\%) and epithelial/parenchymal (28\%) indications (Fig. 1).

\section{Cell processing and delivery mode}

Of all the grafted products reported in detailed form, 51\% were based on expanded cells and in $5 \%$ of the cases cells were transduced (Table 2). About one-third (31\%) of the products was given intravenously, $45 \%$ intraorgan, $14 \%$ on a membrane or gel, and $10 \%$ using a three-dimensional scaffold. 


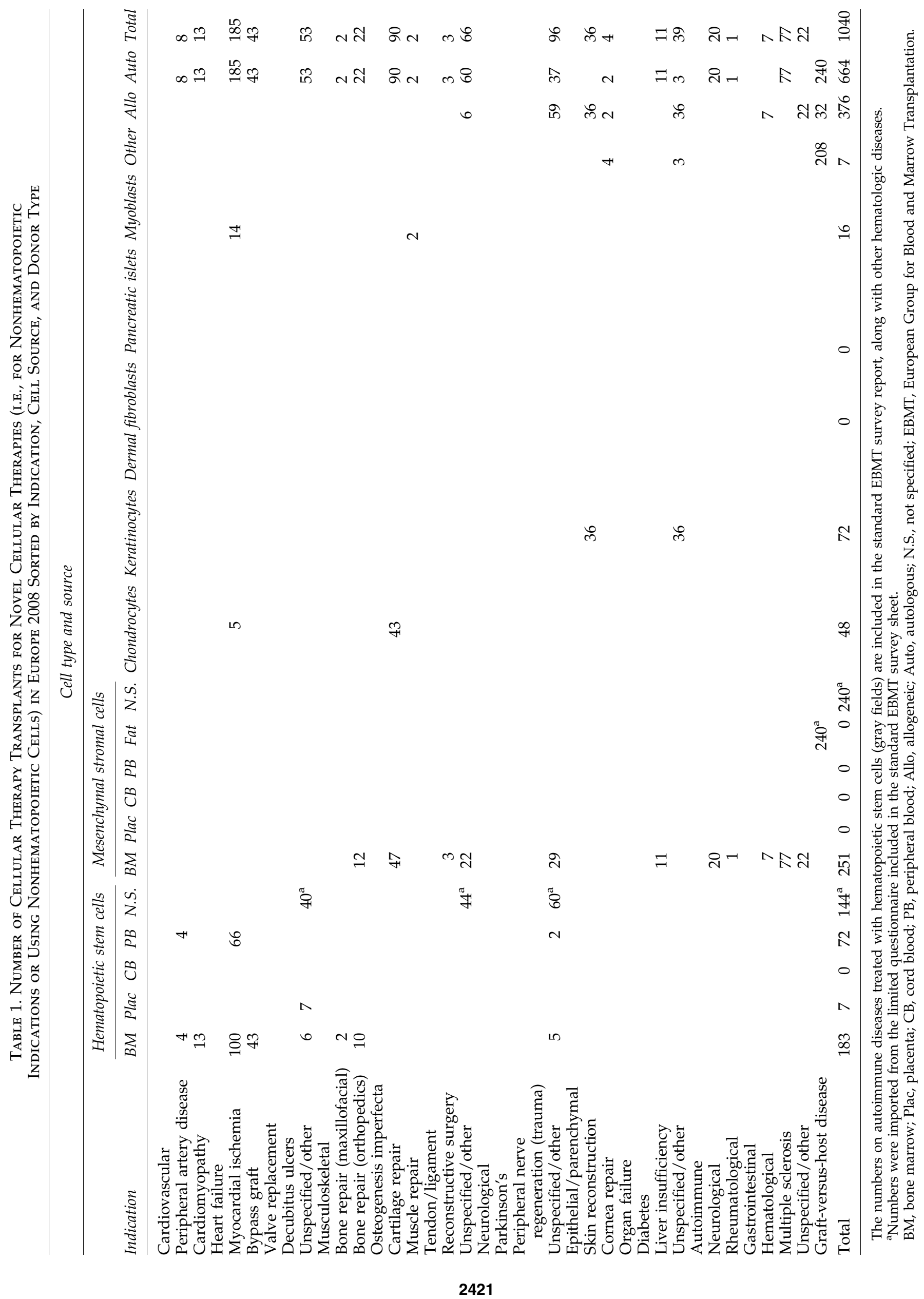


FIG. 1. Percentage of indications for novel cellular therapies in Europe 2008, sorted by donor type. Data used for this chart were derived only from the extended questionnaire.
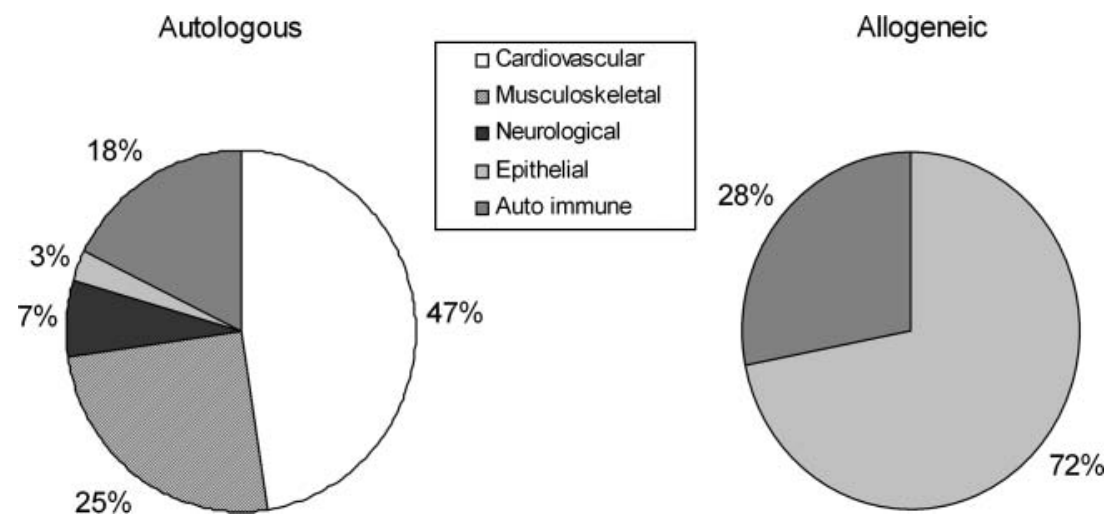

Nonexpanded cells were used to treat $93 \%$ of cardiovascular, $50 \%$ of musculoskeletal, and $19 \%$ of neurological disorders, whereas epithelial/parenchymal and autoimmune diseases were exclusively treated with expanded cells. Beyond a few sporadic exceptions, mostly reported for cardiovascular and musculoskeletal diseases, transplanted cells were not genetically transduced or sorted.

For cardiovascular, neurological, and autoimmune applications, cells were delivered exclusively intravenous or intraorgan (Table 3). The use of a membrane or a gel for cell

Table 2. Number of Cellular Therapy Transplants for Novel Cellular Therapies in Europe 2008 Sorted by Cell Processing Mode

\begin{tabular}{|c|c|c|c|c|c|c|}
\hline \multirow[b]{2}{*}{ Indications } & \multicolumn{6}{|c|}{ Cell processing } \\
\hline & Nonexpanded & Expanded & Untransduced & Transduced & Unsorted & Sorted \\
\hline \multicolumn{7}{|l|}{ Cardiovascular } \\
\hline Peripheral artery disease & 8 & & 8 & & 4 & 4 \\
\hline Cardiomyopathy & 13 & & 13 & & 9 & 4 \\
\hline \multicolumn{7}{|l|}{ Heart failure } \\
\hline Myocardial ischemia & 166 & 19 & 180 & 5 & 185 & \\
\hline Bypass graft & 43 & & 43 & & 43 & \\
\hline \multicolumn{7}{|l|}{ Valve replacement } \\
\hline \multicolumn{7}{|l|}{ Decubitus ulcers } \\
\hline Other & 13 & & & 13 & 13 & \\
\hline \multicolumn{7}{|l|}{ Musculoskeletal } \\
\hline Bone repair (maxillofacial) & 2 & & 2 & & 2 & \\
\hline Bone repair (orthopedics) & 21 & 1 & 22 & & 20 & 2 \\
\hline \multicolumn{7}{|l|}{ Osteogenesis imperfecta } \\
\hline Cartilage repair & 47 & 43 & 86 & 4 & 90 & \\
\hline Muscle repair & & 2 & 2 & & 2 & \\
\hline \multicolumn{7}{|l|}{ Tendon/ligament } \\
\hline Reconstructive surgery & & 3 & & 3 & 3 & \\
\hline Other & & 22 & 22 & & 22 & \\
\hline \multicolumn{7}{|l|}{ Neurological } \\
\hline \multicolumn{7}{|c|}{ Parkinson's } \\
\hline \multicolumn{7}{|c|}{ Peripheral nerve regeneration (trauma) } \\
\hline Other & 7 & 29 & 36 & & 36 & \\
\hline \multicolumn{7}{|l|}{ Epithelial/parenchymal } \\
\hline Skin reconstruction & & 36 & 36 & & 36 & \\
\hline Cornea repair & & 4 & 4 & & 4 & \\
\hline \multicolumn{7}{|l|}{ Organ failure } \\
\hline \multicolumn{7}{|l|}{ Diabetes } \\
\hline Liver insufficiency & & 11 & 9 & 2 & 11 & \\
\hline Other & & 39 & 39 & & 39 & \\
\hline \multicolumn{7}{|l|}{ Autoimmune } \\
\hline Neurological & & 20 & 20 & & 20 & \\
\hline Rheumatological & & 1 & 1 & & 1 & \\
\hline \multicolumn{7}{|l|}{ Gastrointestinal } \\
\hline Hematological & & 7 & 7 & & 7 & \\
\hline Multiple sclerosis & & 77 & 77 & & 77 & \\
\hline Other & & 22 & 22 & & 22 & \\
\hline Total & 320 & 336 & 629 & 27 & 646 & 10 \\
\hline
\end{tabular}

Data only from extended questionnaire. 
Table 3. Number of Cellular Therapy Transplants for Novel Cellular Therapies in Europe 2008 Sorted by Delivery Mode

\begin{tabular}{|c|c|c|c|c|c|}
\hline & \multicolumn{5}{|c|}{ Cell delivery mode } \\
\hline & Intravenous & Intraorgan & Membrane/gel & $3 D$ scaffold & Total \\
\hline \multicolumn{6}{|l|}{ Cardiovascular } \\
\hline Peripheral artery disease & 2 & 6 & & & 8 \\
\hline Cardiomyopathy & 1 & 12 & & & 13 \\
\hline \multicolumn{6}{|l|}{ Heart failure } \\
\hline Myocardial ischemia & 13 & 172 & & & 185 \\
\hline Bypass graft & 26 & 17 & & & 43 \\
\hline \multicolumn{6}{|l|}{ Valve replacement } \\
\hline \multicolumn{6}{|l|}{ Decubitus ulcers } \\
\hline Other & 13 & & & & 13 \\
\hline \multicolumn{6}{|l|}{ Musculoskeletal } \\
\hline Bone repair (maxillofacial) & & 2 & & & 2 \\
\hline Bone repair (orthopaedics) & & 21 & & 1 & 22 \\
\hline \multicolumn{6}{|l|}{ Osteogenesis imperfecta } \\
\hline Cartilage repair & & 12 & 14 & 64 & 90 \\
\hline Muscle repair & & 2 & & & 2 \\
\hline \multicolumn{6}{|l|}{ Tendon/ligament } \\
\hline Reconstructive surgery & & 3 & & & 3 \\
\hline Other & 11 & 11 & & & 22 \\
\hline \multicolumn{6}{|l|}{ Neurological } \\
\hline \multicolumn{6}{|c|}{ Parkinson's } \\
\hline \multicolumn{6}{|c|}{ Peripheral nerve regeneration (trauma) } \\
\hline Other & 31 & 5 & & & 36 \\
\hline \multicolumn{6}{|l|}{ Epithelial/parenchymal } \\
\hline Skin reconstruction & & & 36 & & \\
\hline Cornea repair & & & 4 & & 4 \\
\hline \multicolumn{6}{|l|}{ Organ failure } \\
\hline \multicolumn{6}{|l|}{ Diabetes } \\
\hline Liver insufficiency & 11 & & & & 11 \\
\hline Other & & & 39 & & 39 \\
\hline \multicolumn{6}{|l|}{ Autoimmune } \\
\hline Neurological & 4 & 16 & & & 20 \\
\hline Rheumatological & 1 & & & & 1 \\
\hline \multicolumn{6}{|l|}{ Gastrointestinal } \\
\hline Hematological & 7 & & & & 7 \\
\hline Multiple sclerosis & 62 & 15 & & & 77 \\
\hline Other & 22 & & & & 22 \\
\hline Total & 204 & 294 & 93 & 65 & 656 \\
\hline
\end{tabular}

Data only from extended questionnaire.

3D, three-dimensional.

delivery was only reported for epithelial/parenchymal treatments $(12 \%)$ or for cartilage repair $(2 \%)$. For the group of musculoskeletal indications, all possible cell delivery modes were reported, with a predominant tendency $(46 \%)$ to use a three-dimensional scaffold.

\section{Cellular therapy rates}

Reported cellular therapies were performed in a limited number of countries and with different intensity. Figure 2 displays the cellular therapy rates per 10 million inhabitants in the different European countries. High cellular therapy rates were reported in Belgium, the Netherlands, Slovenia, Switzerland, and Turkey.

\section{Discussion}

The study describes an extension of the previously consolidated EBMT annual activity report, to cover the field of the so-called "novel cellular therapies," namely, the use of nonhematopoietic cells or of HSC for nonhematological indications. The program is still at the experimental stage, and it clearly did not include several teams active in the field of cellular therapy in Europe. Despite this expected initial limit, the initiative provided useful information on some of the trends related to cell-based treatment of various diseases in 2008, which could hardly be captured by analysis of scientific literature.

The survey does not include data on specific indications or patient outcome, and thus the aims are clearly distinct form those of a patient registry. Although the generated map does not offer the possibility of a scientific analysis, the simple structure of the platform and the absence of intellectual property or commercial issues should encourage the contribution by most academic and commercial groups. In this regard, we deem as a remarkable outcome that already five consolidated and large societies have joined forces toward the establishment of the program. 
FIG. 2. Cellular therapy rates (number of cellular therapies per 10 million inhabitants) for novel cellular therapies in Europe 2008.

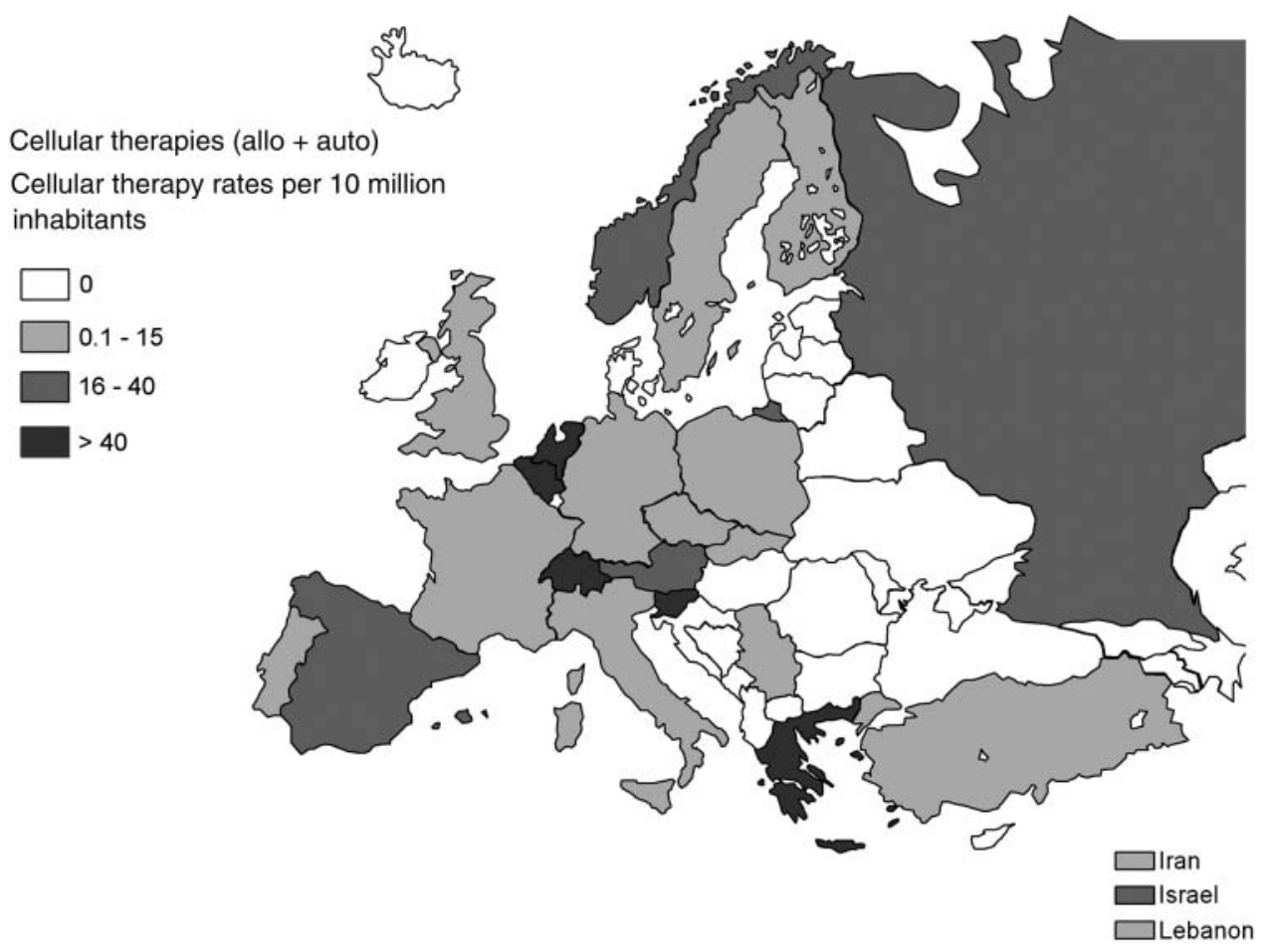

Overall, the presented data highlight a relatively large activity in the clinical use of cell therapies, even in areas where scientific data have not yet established a benefit for the patient. To consolidate and further extend this initiative, additional working groups will be invited to participate. Moreover, it will be made more clear that reports for novel cellular therapies will all have to be claimed using the detailed form as opposed to the standard EBMT one. Next year's report, based on cell-based therapies performed in 2009, should thus more thoroughly capture the effective patient numbers and the modes of cell processing and delivery. This European program is also expected to stimulate parallel activities in other geographical areas, including the North American, Asian-Pacific, and economically emerging countries.

\section{Acknowledgments}

We greatly appreciate the cooperation of all participating teams and their staff (listed in the Appendix) and the engagement of the different working groups and their highly committed representatives, namely, TERMIS-EU (Sarah Wilburn), ISCT-Europe (Francesco Lanza and Ineke Slaper), ICRS (Daniel Saris and Stephan Seiler), EBMT, and EULAR.

The work was supported in part by the European Leukaemia Net (LSH-2002-2.2.0-3), the Swiss National Research Foundation (3200B0-118176), the Swiss Cancer League, the Regional Cancer League, and the Horton Foundation.

EBMT is supported by grants from the corporate members: Amgen Europe GmbH, ViroPharma Europe, Celegene International SARL, Genzyme Europe B.V., Gilead Sciences Europe Ltd., Miltenyl Biotec GmbH, F. Hoffmann-La Roche, Schering-Plough International Inc., Bristol Myers Squibb, CaridianBCT Europe NV, Cephalon Europe, Fresenius Biotech $\mathrm{GmbH}$, Therakos Inc., Alexion Europe, Chugai Sanofi-
Aventis, Merck Sharp and Dohme, Novartis, Pfizer, and Pierre Fabre Médicament.

\section{Disclosure Statement}

There are no conflicts of interest to declare.

Writing of this article was the sole responsibility of the authors.

\section{References}

1. Gratwohl, A. Bone marrow transplantation activity in Europe 1990. Report from the European Group for Bone Marrow Transplantation (EBMT). Bone Marrow Transplant 8, 197, 1991.

2. Gratwohl, A., Baldomero, H., Horisberger, B., Schmid, C., Passweg, J., and Urbano-Ispizua, A. Accreditation Committee of the European Group for Blood and Marrow Transplantation (EBMT). Current trends in haematopoietic stem cell transplantation in Europe. Blood 100, 2374, 2002.

3. Copelan, E.A. Hematopoietic stem-cell transplantation. N Engl J Med 354, 1813, 2006.

4. Appelbaum, F.R. Hematopoietic-cell transplantation at 50. N Engl J Med 357, 1472, 2007.

5. Gratwohl, A., Baldomero, H., Schwendener, A., Gratwohl, M., Apperley, J., Niederwieser, D., Frauendorfer, K., and Joint Accreditation Committee of the International Society for Cellular Therapy; European Group for Blood and Marrow Transplantation; European Leukemia Net. Predictability of hematopoietic stem cell transplantation rates. Haematologica 92, 1679, 2007.

6. Gratwohl, A., Baldomero, H., Schwendener, A., Rocha, V., Apperley, J., Frauendorfer, K., and Niederwieser, D. The EBMT activity survey 2007 with focus on allogeneic HSCT for AML and novel cellular therapies. Bone Marrow Transplant 43, 275, 2009. 
7. Bernardo, M.E., Locatelli, F., and Fibbe, W.E. Mesenchymal stromal cells. Ann NY Acad Sci 1176, 101, 2009.

8. Novotny, N.M., Ray, R., Markel, T.A., Crisostomo, P.R., Wang, M., Wang, Y., and Meldrum, D.R. Stem cell therapy in myocardial repair and remodeling. J Am Coll Surg 207, 423, 2008.

9. van Ramshorst, J., Bax, J.J., Beeres, S.L., Dibbets-Schneider, P., Roes, S.D., Stokkel, M.P., de Roos, A., Fibbe, W.E., Zwaginga, J.J., Boersma, E., Schalij, M.J., and Atsma, D.E. Intramyocardial bone marrow cell injection for chronic myocardial ischemia: a randomized controlled trial. JAMA 301, 1997, 2009.

10. Einstein, O., and Ben-Hur, T. The changing face of neural stem cell therapy in neurologic diseases. Arch Neurol 65, 452, 2008.
Address correspondence to: Ivan Martin, Ph.D.

Institute for Surgical Research and Hospital Management University Hospital Basel

CH-4031 Basel

Switzerland

E-mail: imartin@uhbs.ch

Received: January 31, 2010

Accepted: February 25, 2010

Online Publication Date: March 25, 2010

\title{
APPENDIX
}

List of Reporting Novel Cellular Therapy Centers in Europe in 2008

\author{
Austria \\ Graz, Universitäts Kinderklinik, Ch. Urban $(3 ; 3 / 0)^{\mathrm{a}}$ \\ Graz, University of Graz, W. Linkesch $(4 ; 4 / 0)^{\mathrm{a}}$ \\ Vienna, St. Anna Kinderspital, H. Gadner, C. Peters $(1 ; 1 / 0)^{a}$ \\ Vienna, Medical University Hospital, S. Marlovitis (7; 0/7) \\ Belgium \\ Antwerpen, Suivenberg ZH, P. Zachee (3; 3/0) \\ Antwerpen, Uiversity Antwerpen, W. Schroyens $(1 ; 1 / 0)^{\mathrm{a}}$ \\ Brugge, A.Z. St. Jan, D. Selleslag, A.v. Hoof, J.v. Droogenbroeck, K.v. Eygen $(2 ; 2 / 0)^{a}$ \\ Brussels, Military Hospital Queen Astrid Gilbert Verbeken (72; 72/0) \\ Edegem, Center for Cellular Therapy and Regenerative Medicine, V. van Tendeloo $(2 ; 1 / 1)$ \\ Leuven, University Hospital Gasthuisberg, G. Verhoef, M. Delforge, J. Maertens $(5 ; 5 / 0)^{a}$ \\ Liège, University Hospital Sart-Tilman, Y. Béguin, B. de Prijck $(16 ; 16 / 0)^{\mathrm{a}}$ \\ Czech Republic \\ Olomouc, University Hospital, K. Indràk $(4 ; 0 / 4)^{\text {a }}$ \\ Finland \\ Helsinki, Helsinki University Central Hospital, L. Volin $(4 ; 0 / 4)^{\mathrm{a}}$ \\ Helsinki, Children's Hospital, U. Pihkala, K. Vettenranta $(1 ; 1 / 0)^{\text {a }}$ \\ France \\ Clermont Ferrand, Centre Hospitalier Universitaire, Hôtel Dieu, F. Demeocq (14; 0/14) \\ Grenoble, Hospitalier A. Michallon, J.Y. Cahn, F. Garban, P. Drillat, D. Plantaz (1; 0/1) ${ }^{\mathrm{a}}$ \\ Grenoble, Saint Ismier, M.-J. Richard (1;0/1) \\ Nancy, Vandoeuvre-les-Nancy, CHU Nancy-Brabois, P. Lederlin, F. Witz (5; 0/5) \\ Paris, Hopital St. Louis, J. Larghero (2;0/2) \\ Poitiers, Hôpital Jean Bernard, La Miletrie, M. Renaud $(1 ; 0 / 1)^{\text {a }}$ \\ Germany \\ Berlin, Universitäts-Klinik Benjamin Franklin, E. Thiel, L. Uharek $(8 ; 5 / 3)^{\mathrm{a}}$ \\ Darmstadt, Evangelisches Krankenhaus, Dr. Schreyer $(4 ; 0 / 4)$ \\ Dresden, Universitätsklinikum Carl Gustav Carus, Med. Poliklinik, G. Ehninger, H. Bornhäuser $(1 ; 0 / 1)$ \\ Dresden, Universitätsklinikum Carl Gustav Carus, Hematology, G. Ehninger, H. Bornhäuser $(14 ; 14 / 0)^{\mathrm{a}}$ \\ Düsseldorf, Heinrich-Heine University, D. Dilloo, H.J. Laws, A. Borkhardt $(1 ; 1 / 0)^{\mathrm{a}}$ \\ Frankfurt, Universitätsklinikum d. J.W. Goethe, T. Klingebiel, P. Bader $(1 ; 1 / 0)^{\mathrm{a}}$ \\ Halle, Clinic Bergmannstrost, H.J. Meisel (7; 0/7) \\ Hamburg, Eppendorf-Krankenhaus, A.R. Zander, N. Kröger $(2 ; 2 / 0)^{\mathrm{a}}$ \\ Hannover, Medizinische Hochschule, A. Ganser, M. Eder $(3 ; 3 / 0)^{\mathrm{a}}$ \\ Heidelberg, Universitäts-Poliklinik, A.D. Ho, P. Dreger $(1 ; 1 / 0)^{\mathrm{a}}$ \\ Köln, Universitäts-Klinik, M. Hallek, Ch. Scheid, F. Berthold, T. Simon $(3 ; 0 / 3)^{\text {a }}$ \\ Tübingen, Medizinische Universitäts-Klini (ads), L. Kanz, C. Faul $(2 ; 2 / 0)^{\mathrm{a}}$ \\ Tübingen, Medizinische Universitäts-Klinik (peds), R. Handgretinger, P. Lang (16; 16/0) ${ }^{\mathrm{a}}$ \\ Ulm, Kinderklinik der Universität, W. Friedrich, K. Debatin $(1 ; 1 / 0)^{\mathrm{a}}$ \\ Wiesbaden, Deutsche Klinik für Diagnostik, R. Schwerdtfeger, M. Schleuning $(3 ; 3 / 0)^{a}$ \\ Greece \\ Athens, Academy of Athens, A. Papassavas (30;0/30) \\ Athens, Evanghelismos Hospital, D. Karakasis, N. Harhalakis, E. Nikiforakis $(2 ; 2 / 0)^{a}$
}


Athens, Aghia Sophia Children's Hospital, S. Graphakos (4; 0/4)

Thessaloniki, The George Papanicolaou General Hospital, A.S. Fassas $(2 ; 0 / 2)$

Thessaloniki, Sports Clinic, Emanuel T. Papacostas (6; 0/6)

Iran, Islamic Rep.

Teheran, Shariati Hospital A. Ghavamzadeh (10;0/10)

Teheran, Shariati Hospital A. Ghavamzadeh $(25 ; 25 / 0)^{a}$

Israel

Jerusalem, Hadassah University Hospital, R. Or, S. Slavin (12; 12/0) a

Petach-Tikva, Beilinson Hospital, M. Yeshurun $(1 ; 1 / 0)^{\mathrm{a}}$

Italy

Bologna, 6th div Rizzoli Orthopedic Institute, S. Giannini, R. Buda (47; 0/47)

Firenze, Policlinico di Careggi, A. Bosi, S. Guidi (12; 0/12)

Monza, Ospedale S. Gerardo, C. Uderzo $(2 ; 2 / 0)^{a}$

Pesaro, Ospedale San Salvatore, G. Visani $(6 ; 6 / 0)^{\mathrm{a}}$

Piacenza, Ospedale Civile, L. Capanna $(6 ; 0 / 6)$

Reggio di Calabria, Azienda Ospedale "Riuniti e Morelli", Bianchi-Melacrino, P. Iacopino $(1 ; 0 / 1)$

Roma, Università Cattolica, S. Cuore, S. Sica, G. Leone $(1 ; 1 / 0)^{\mathrm{a}}$

Torino, University Hospital, F. Fagioli, E. Vassallo $(1 ; 1 / 0)^{\mathrm{a}}$

Lebanon

Beirut, American University of Beirut, A. Bazarbachi $(5 ; 0 / 5)$

Netherlands

Leiden, University Hospital, R. Willemze, M. Egeler $(48 ; 13 / 35)^{\mathrm{a}}$

Nijmegen, University Hospital, A. Schattenberg, P. Hoogerbrugge $(1 ; 0 / 1)^{\mathrm{a}}$

Utrecht, University Hospital, L.F. Verdonck, N.M. Wulffraat (14; 0/14)

Utrecht, Erasmus University Medical Center, Wim J. van der Giessen (135; 0/135)

Norway

Oslo, University Hospital Rikshospitalet, J. Brinchmann (10; 0/10)

Poland

Cracow, University Children's Hospital JUMC, J. Gozdzik $(1 ; 1 / 0)^{\mathrm{a}}$

Portugal

Lisbon, Instituto Portugues de Oncologia, M. Abecasis $(4 ; 4 / 0)^{\mathrm{a}}$

Russian Fed.

Moscow, Russian Children's Hospital, A. Maschan, E. Skorobogato, E. Pachanov $(7 ; 7 / 0)^{a}$

Moscow, Cancer Research centre, G. Mentrevich (59; 59/0) ${ }^{\mathrm{a}}$

Moscow, Main Military Clinical Hospital, S.V. Shamansky, O.A. Rukavitcin $(1 ; 0 / 1)^{\mathrm{a}}$

Moscow, Research Haematology Center of RAS, V.G. Savtchenko $(5 ; 5 / 0)$

Novosibirsk, Inst. Clinical Immunolgy, I. Lisukov $(19 ; 4 / 15)^{\mathrm{a}}$

St. Petersburg, Trans-Technologies Inc., Andrey V. Krylov $(144 ; 22 / 122)$

St. Petersburg, Pavlov Medical University, B.V. Afanassiev, L. Zubarovskaya (14; 0/14)

St. Petersburg, Pavlov Medical University, B.V. Afanassiev, L. Zubarovskaya $(14 ; 14 / 0)^{a}$

Serbia

Belgrade, Military Medical Academy, D. Stamatovic (7; 0/7)

Slovak Republic

Bratislava, National Cancer Institute, J. Lakota $(1 ; 1 / 0)^{\mathrm{a}}$

Slovenia

Ljublijana, University Medical Centre, J. Pretnar (10;0/10)

Ljublijana, Educell d.o.o, N. Kregar-Velikonja (14; 0/14)

Spain

Barcelona, Hospital Clinic, E. Carreras $(2 ; 2 / 0)^{\mathrm{a}}$

Cordoba, Hospital Reina Sofia, A. Torres-Gomez (16; 0/16)

Cruces-Barakaldo, Hospital de Cruces, I. Zuazua.Verde, F. Floristan $(17 ; 0 / 17)^{a}$

Granada, Hospital Virgen de la Nieve, J.M. De Pablos Gallego, M. Jurado Chacon $(1 ; 1 / 0)^{\mathrm{a}}$

Madrid, Hospital de la Princesa, A. Figuera, A. Alegre $(7 ; 0 / 7)^{\mathrm{a}}$

Madrid, Hospital La Paz, A. Martinez, A. Sastre, R. Arrieta $(3 ; 1 / 2)^{a}$

Madrid, Hospital General Universitario Gregorio Maranon, J.L. Diez-Martin $(1 ; 1 / 0)^{\mathrm{a}}$

Murcia, Hospital Virgen de la Arrixaca, J.M. Moraleda, A. Morales Lazaro (10; 0/10)

Palma de Mallorca, Hospital Son Dureta, J. Besalduch, M. Canaro $(6 ; 6 / 0)^{a}$

Pamplona, Clinica Universitaria de Navarra, J. Rifon $(21 ; 1 / 20)$

Salamanca, Complejo Hospital, D. Caballero (11; 11/0) ${ }^{\mathrm{a}}$

Sweden

Lund, University Hospital, S. Lenhoff $(2 ; 2 / 0)^{\mathrm{a}}$

Stockholm, Karolinska University Hospital, Huddinge, P. Ljungman $(5 ; 5 / 0)^{\mathrm{a}}$

Switzerland

Geneva, Hôpital Cantonal Universitarie, J. Passweg, Y. Chalandon $(8 ; 1 / 7)^{\mathrm{a}}$

Lugano, Cardiocentro Ticino, G. Astori $(26 ; 0 / 26)$ 
List of Reporting Novel Cellular Therapy Centers in Europe in 2008 (Continued)

Turkey

Adana, Baskent University Adana, H. Ozdogu, C. Boga (2; 2/0)

Ankara, Ihsan Dogramaci Children's Hospital (Hacettepe), A. Tuncer, D. Uckan $(1 ; 1 / 0)^{a}$

United Kingdom

Cambridge, Addenbrooke's Hospital, C. Crawley, R.E. Marcus, J. Craig $(2 ; 2 / 0)^{a}$

Leeds, St. James's University Hospital + The General Infirmary, M. Gilleece, S. Kinsey $(2 ; 2 / 0)^{\mathrm{a}}$

Format: city, hospital, physician (total treatments; allogeneic/autologous).

${ }^{a}$ Numbers and teams were imported from the limited questionnaire included in the standard European Group for Blood and Marrow Transplantation survey sheet. 
